\title{
VISIBILIDADE TENSIONADA: PROSUMIDORES, ATIVISMO VIRTUAL E A PRESSÃO CONTRA POSTURAS ORGANIZACIONAIS NEGATIVAS
}

\author{
Carolina dos Santos Ferreira ${ }^{1}$ \\ Wellington Teixeira Lisboa $^{2}$
}

\begin{abstract}
Resumo: Esta pesquisa apresenta uma análise sobre as práticas de ativismo processadas na internet, com foco particular na ação dos prosumers. Nessa perspectiva, articula reflexões teóricas e contextuais em torno dos campos do ativismo, do consumo e das novas tecnologias da informação e comunicação, também apontando as implicações dessa relação no âmbito organizacional. A metodologia deste estudo baseia-se em duas partes interdependentes: a primeira referente a uma revisão da bibliografia sobre os temas centrais da pesquisa; a segunda concernente a um estudo empírico, de natureza qualitativa, em que se explora a forma como os prosumers ativistas do caso "Ades de maça", alusivo à adulteração do conteúdo líquido de um lote de suco dessa marca, manifestaram-se frente a esse acontecimento, pela produção de vídeos na plataforma Youtube.
\end{abstract}

Palavras-chave: Ativismo virtual, prosumer, reputação institucional.

\begin{abstract}
This research presents an analysis of the activism practices processed on the Internet, with particular focus on the action of prosumers. From this perspective, it articulates theoretical and contextual reflections around the fields of activism, consumption and new technologies of information and communication. It also pointing out the implications of this relationship in the organizational context. The methodology of this study is based on two interdependent parts: the first refers to a review on the central themes of research; the second concerns an empirical study of qualitative nature, as it explores how activist prosumers coped with the affair "Ades", alluding to the adulteration of the liquid contents of a lot of juice of this brand, speaking out against this event, as well as producing videos on Youtube platform about that matter.
\end{abstract}

Keywords: Virtual activism, prosumer, institutional reputation.

\section{Introdução}

O ativismo, numa acepção geral, refere-se a manifestações sociais, individuais e coletivas, de cunho ideológico, que ocorrem em serviço de uma causa ou doutrina (MACHADO, 2007). Atualmente, observamos o constante crescimento desses movimentos, em diversas atuações possíveis, como na esfera ambiental, política, jurídica, tecnológica, sociocultural, no campo da democratização e condições do consumo, entre outras, inclusive contra práticas organizacionais que violam direitos humanos historicamente conquistados.

No panorama empresarial, em particular, a comunicação revela-se como essencial nas dinâmicas de mobilização e luta por parte dos consumidores, comunidades e por diversos públicos de relacionamento, nas suas variadas práticas de ativismo, assim como possibilita a

\footnotetext{
${ }^{1}$ Graduada em Relações Públicas pela Universidade Católica de Santos. Foi Bolsista de Iniciação Científica pelo Conselho Nacional de Desenvolvimento Científico e Tecnológico (CNPq).

${ }^{2}$ Professor da Universidade Católica de Santos. Orientador desta pesquisa de Iniciação Científica na Universidade Católica de Santos. Doutor em Sociologia pela Universidade Estadual de Campinas (Unicamp) e mestre em Comunicação e Jornalismo pela Universidade de Coimbra.
} 
DITO EFEITO - ISSN 1984-2376 -v. 6, n. 9, jul./dez. 2015-UTFPR CURITIBA -

http://periodicos.utfpr.edu.br/de

conscientização e o esclarecimento sobre os posicionamentos organizacionais (FORTES, 2003; GRUNIG, 2011). Para Henriques (2007, p. 92), “A comunicação tem destacado papel nesse contexto, seja devido aos processos de visibilidade midiática, seja pela necessidade de compor estratégias de relacionamento com os públicos desses movimentos em torno de suas causas".

Portanto, dada a conjuntura social contemporânea, caracterizada pela possibilidade de crescente interação entre consumidores-ativistas-organizações (MORAES, 2007; KAUFMAN, 2013), existe a necessidade de as instituições, de qualquer setor ou porte, saberem se comunicar e se relacionar adequadamente com os seus diversos públicos (FRANÇA, 2011), a exemplo dos ativistas, sobretudo porque têm sido recorrentes os exemplos de organizações que, por alguma falha na composição de seu produto ou por interpretação de viés negativo que fazem de suas campanhas publicitárias, sofrem problemas graves de reputação institucional.

Com a configuração do que Manuel Castells (1999) denomina como "sociedade em rede", amparada pelas novas tecnologias de informação e comunicação, os problemas no âmbito empresarial que põem em xeque a dignidade humana, a convivência social e que degradem o meio ambiente podem ganhar repercussões em nível nacional ou mesmo internacional, em questão de segundos. Henrique Mazetti (2013), na mesma linha de Castells (1999) e Lévy (1999), afirma que a comunicação e suas novas formas de tecnologia tornaram-se princípios organizadores da sociedade. Em outras palavras, vivemos em uma época ambientada pelas mídias, por sua convergência, como apregoa Jenkins (2008), tanto em seu caráter infraestrutural, em que os meios de comunicação assumem o sentido de base material para a composição do social, ao oferecer redes de telecomunicações, satélites e fibras óticas como suporte para rápidos fluxos de informação, trocas de dados e operações econômicas; assim como por meio da cultura midiática, que fornece material para a cristalização de comportamentos sociais, fermentação de opiniões políticas e construção de identidades.

A importância desta pesquisa, nesse quadro, revela-se pelo fato de discutir a centralidade da comunicação nos vínculos entre organizações e a sociedade, sobretudo num contexto de pluralidade de formas de mobilização social e das demandas por empresas com postura ética e responsável (FARIAS, 2011). As manifestações coletivas em torno de uma causa ganham proporção inimaginável com as tecnologias de informação e comunicação, o que requer o estudo tanto dos canais por meio dos quais se processam essas discussões e as repercussões geradas por essa pressão, objetivo da presente reflexão, quanto da postura das organizações frente a essa realidade. A plataforma virtual, pois, vem se configurando como um locus onde os consumidores e outros grupos se manifestam, se organizam e questionam, das mais diversas 
DITO EFEITO - ISSN 1984-2376 -v. 6, n. 9, jul./dez. 2015-UTFPR CURITIBA -

http://periodicos.utfpr.edu.br/de

formas, em relação aos mais diversos assuntos e causas, instigando as pesquisas no campo das Ciências Sociais e Humanas.

Nesse sentido, esta pesquisa visa compreender as práticas de ativismo processadas na internet, com foco particular na ação dos prosumers da marca Ades, da Unilever, e os conteúdos produzidos por eles no canal YouTube, frente ao problema da adulteração do conteúdo líquido do suco de sabor "maçã", ocorrido em 2013. Este caso envolveu a contaminação, por produtos de limpeza, de 96 unidades de Ades sabor "maçã", 1,5 litro, lote AGB25, produzidas na linha TBA3G, na fábrica de Pouso Alegre, Minas Gerais. Houve consumidores que ingeriram o suco e tiveram complicações de saúde, sendo que o ocorrido teve repercussões midiáticas em âmbito nacional, gerando inúmeras manifestações individuais e coletivas frente à marca Ades, por diversos canais.

Assim, pretende-se, neste texto, problematizar as diferentes formas pelas quais os ativistas mobilizam-se ante as falhas e problemas empresariais com impactos sociais; compreender a dinâmica do ativismo na internet, precisamente na plataforma Youtube e analisar a ação dos prosumidores nas redes digitais e sua vinculação com o ativismo. A metodologia deste estudo baseia-se em duas partes interdependentes: a primeira diz respeito a uma revisão da bibliografia sobre os temas centrais a esta pesquisa, como ativismo, prosumer, ciberespaço, novas tecnologias da comunicação, reputação institucional; a segunda concerne a um levantamento, seguido de análise qualitativa, dos vídeos postados no canal YouTube até 10 de janeiro de 2014 (recorte temporal em razão, meramente, do cronograma e viabilidade da pesquisa), com referência ao caso de adulteração do conteúdo líquido do suco de sabor "maçã" da marca Ades.

\section{As reconfigurações do ativismo e do consumo na contemporaneidade}

Os ativistas exercem ações voltadas a uma causa coletiva, em prol de "um conjunto de interesses e valores comuns, com o objetivo de definir e orientar as formas de atuação social" (MACHADO, 2007, p. 252). Em geral, possuem diferentes tipos de atuação, que podem variar desde denúncias, pressões regulares, abaixo-assinados pontuais, até passeatas, manifestações de um pequeno ou grande grupo, ocupações de espaços públicos, boicotes a produtos e empresas e outras ações direcionadas, como os debates com governantes em audiências públicas. 
DITO EFEITO - ISSN 1984-2376 -v. 6, n. 9, jul./dez. 2015-UTFPR CURITIBA -

http://periodicos.utfpr.edu.br/de

Segundo Machado (2007), os movimentos sociais, que são uma das faces mais visíveis e organizadas das práticas do ativismo, atuam numa dinâmica que confere empoderamento aos atores "comuns" da sociedade, já que possibilitam a expressão da indignação quanto a atitudes de natureza e origens diversas, que podem comprometer o meio ambiente, natural e social, e os interesses da coletividade. O ativismo em grupo, comumente conhecido por movimentos sociais, é um importante instrumento transformador de hábitos, pensamentos e costumes, pois exerce pressão para melhoria das condições de vida e é um dos responsáveis pela prática da cidadania, que é o exercício dos direitos e deveres na relação indivíduo-Estado, numa explicação bastante genérica (MACHADO, 2007).

No Brasil, na virada do século 19 para o 20, ganhando força ao longo deste último século, estruturaram-se os sindicatos e movimentos do proletariado, contrários a condições opressoras que lhes foram impostas no ambiente fabril, contando com o apoio de jornais dos operários e outros veículos de comunicação alternativos, como uma das suas armas de mobilização política (PERUZZO, 2004). Podemos citar, também, os movimentos das décadas de 1960 a 1990, quando ocorreram as mobilizações da sociedade civil que culminaram nas "diretas já", que até hoje é considerado um dos mais expressivos movimentos sociais de abrangência nacional, ocorrido na década de 1980, incentivado por partidos políticos que tinham sido recém-criados, intelectuais e artistas que foram às ruas com a população para se manifestar pelo direito do voto direto nas eleições presidenciais.

Outro acontecimento histórico em termos de mobilização da sociedade pode ser assinalado relativamente à campanha "fora Collor", de 1992, que conclamou a retirada do governo do então presidente da República, Fernando Collor de Mello; assim como os movimentos estudantis da União Nacional dos Estudantes (UNE) constituíram-se como dinâmicas sociais de relevo para se pensar o ativismo no Brasil (PERUZZO, 2004). Na concepção de Maria da Glória Gohn (2011, p. 335), os movimentos sociais caracterizam-se como "ações sociais coletivas de caráter sócio-político e cultural que viabilizam formas distintas de a população se organizar e expressar suas demandas".

As causas podem ser a favor de grupos ou temas específicos ou até mesmo em prol de uma nação, como a mobilização dos "20 centavos", que aconteceu em 2013, em inúmeras cidades brasileiras, inicialmente em torno do aumento das tarifas de transporte público; a Primavera Árabe, movimento contra a ditadura nos países Árabes, que começou na Tunísia e depois se estendeu à Líbia, Egito, Argélia, Iêmen, Marrocos, Bahrein, Síria, Jordânia e Omã, desde 2010. Esses acontecimentos recentes têm sido organizados, atualizados, realimentados, 
DITO EFEITO - ISSN 1984-2376 -v. 6, n. 9, jul./dez. 2015-UTFPR CURITIBA -

http://periodicos.utfpr.edu.br/de

não exclusivamente, mas também por meio da plataforma virtual, que vem possibilitando maior interatividade entre as pessoas e instituições e a configurações de pressões inimagináveis.

Embora seja uma mídia que viabiliza a comunicação para uma grande quantidade de pessoas, muitas vezes localizadas em pontos geográficos os mais distintos, a internet possui um diferencial dos outros dispositivos comunicacionais considerados "tradicionais", como a rádio e a "televisão", por oferecer, em certa medida, uma forma de poder aos cidadãos. Além de permitir a interação e o debate, que até podem ser monitorados ou censurados, dependendo da rede e das condições de acesso, a plataforma virtual, que nos termos adotados por Lévy (1999) pode ser denominada como ciberespaço, permite que o próprio internauta crie o seu conteúdo na esfera online, outorgando-lhe condições de apropriar-se de funções típicas a produtores de conteúdos e ideias.

Lévy (2012) chega a afirmar que o ciberespaço possibilitou uma nova forma de atuação e de debate no e sobre os espaços públicos, promovendo a renovação da produção de informações e de deliberação política, o que o leva a crer que os cotidianos das sociedades contemporâneas são tecidos e negociados, também, nesse território que mais parece uma "ágora online". Desse modo, ao promover a ciberdemocracia, a internet suscita o empoderamento dos cidadãos e, por consequência, o fortalecimento da pressão social pelo fim da censura imposto por regimes autoritários de governo. "Pode-se levantar a hipótese de que em um país no qual $25 \%$ da população estejam conectados à internet não poderia mais manter uma ditadura" (LÉVY, 2012, p. 372).

Uma vez empoderados pelas possibilidades comunicativas e conectivas (CASTELLS, 1999; LÉVY, 2012), os cidadãos podem pressionar organizações e governos para uma conduta mais transparente e ética, inclusive solicitando a resolução de problemas que acometam a dignidade humana e a saúde do meio ambiente social e natural. Como contextualiza Daniel Silva (2007), as manifestações do século 20 já procuravam utilizar a massificação da comunicação como forma de transmitir suas ideias e ações.

\footnotetext{
Da popularização e massificação da imprensa até a implementação da comunicação mediada por computadores, o uso de mídias como forma de transmitir informações e conhecimento para outras pessoas distantes no espaço ou no tempo sempre foi objeto de grande interesse social (SILVA, 2007, p. 02).
}

Assim, as ferramentas tecnológicas infocomunicacionais podem potencializar as ações de um grupo formado por poucos ou muitos indivíduos, que podem ser desencadeadas e partilhadas pelos mais diversos atores sociais. Significa dizer que a entrada desses grupos no ciberespaço aumentou consideravelmente a divulgação das suas ações e ideias, contribuindo 
DITO EFEITO - ISSN 1984-2376 -v. 6, n. 9, jul./dez. 2015-UTFPR CURITIBA -

http://periodicos.utfpr.edu.br/de

para o fortalecimento e formação de novos grupos de pressão, pois ocasionou o encontro dos atores que antes estavam dispersos.

a possibilidade de comunicação rápida, barata e de grande alcance faz atualmente da internet o principal instrumento de articulação e comunicação das organizações da sociedade civil, movimentos sociais e grupos de cidadãos (MACHADO, 2007, p. 268).

Como exemplo dessa amplificação das manifestações da sociedade, potencializadas pela internet, podemos citar também as campanhas para compartilhamento de determinadas ideias, abaixo assinados on-line e o surgimento de novos movimentos sociais, como a rede Anonymous e o Avaaz. O Anonymous é um movimento de ativistas internacionalmente conhecido e que possui ações em diversos países. É um grupo de hackers que se considera hackivistas, ou seja, ativistas da internet. São conhecidos por disseminarem informações sigilosas e invadirem redes de dados do governo ou de outras instituições. Por sua vez, o Avaaz é uma comunidade também internacional e de ações on-line, cujos membros encaminham e assinam petições, organizam manifestações, telefonam e enviam e-mails para governos, cobrando responsabilidades no que diz respeito às funções e deveres atrelados ao bem público. O papel dessas duas redes para o sucesso de grupos ativistas parece-nos fundamental, por viabilizarem e legitimarem muitas iniciativas de interesse social e de tornarem-nas mais conhecidas.

Outras redes que viabilizam as ações pela internet são os sites abaixoassinado.org e peticaopublica.com.br, que propiciam espaço para criação de documentos de contestação e reinvindicação em prol de diversas causas, como a proteção animal e ambiental, sobre política e legislação e sobre assuntos mais gerais e diversificados, como abaixo-assinado pelo fim do horário brasileiro de verão, mudança no cardápio de universidades públicas, aumentos de salários a determinada classe laboral, etc.

Iniciativas como essas reforçam a ideia do empoderamento de pessoas "comuns" e da rede de articulação que pode derivar dessa relação de poder, como também descreve Machado (2007, p. 262):

\footnotetext{
Atualmente, ferramentas tecnológicas potencializam enormemente a ação de um mero punhado de indivíduos. Tal cenário aponta para conflitos de difícil mediação, marcados pela ação e organização virtual, eletrônica, cada vez mais desterritorializadas, desencadeada pelos mais diversos atores sociais - muitas vezes insuspeitos.
}

Nesse cenário, muitas empresas vêm se deparando com manifestações negativas, pela internet, de consumidores e de outros públicos (FRANÇA, 2011) em relação aos problemas nos 
DITO EFEITO - ISSN 1984-2376 -v. 6, n. 9, jul./dez. 2015-UTFPR CURITIBA -

http://periodicos.utfpr.edu.br/de

serviços e produtos que lhes são prestados. Isso porque a plataforma virtual, como temos enfatizado neste estudo, configura-se como um território onde os cidadãos consumidores, em outras palavras, os prosumers, podem questionar, registrar sua indignação, produzir conteúdos em áudio, texto, imagens, acionar redes de contatos, participar e influenciar pessoas e movimentos que cobram a responsabilidade nos posicionamentos organizacionais. Importa-nos ressaltar que os prosumers, termo de origem inglesa que atualmente vem sendo utilizado por pesquisadores do tema do consumo para definir os "consumidores que interferem de alguma forma na formação de opinião da marca/produto/serviço" (MOTTA; BATISTA, 2013, p. 39), se fortaleceram com o advento do ciberespaço. Os sites de compras, por exemplo, possibilitam aos seus consumidores e clientes analisarem o produto/serviço que está sendo oferecido, comentando-o na plataforma virtual.

A possibilidade de poder ler e comentar sobre o produto que se consome ou sobre a marca aumenta a capacidade de decisão do consumidor, pois este pode analisar opiniões diversas antes de realizar a compra e comparar a informação prestada pela marca/produto e as informações prestadas pelos prosumidores, consumidores produtores de conteúdo e opinião (DOMINGUES, 2013). Esse fato reforça a ideia de que o prosumidor ativista, além de influenciar na formação da imagem da marca, pressiona para que as organizações prestem informações verdadeiras e serviços da melhor qualidade possível.

Nesse sentido, consideramos prosumidor ativista aquele que se manifesta contra determinadas ações de uma organização e produto, a fim de alertar sobre práticas e condutas de cunho negativo e forçar mudanças nas instituições, na perspectiva da responsabilidade social e ambiental. Kaufman e Roza (2013, p.19) compartilham desse pensamento, alegando que:

o consumidor atual, quando se vê diante da necessidade de exercer uma preferência de qualquer natureza, geralmente consulta as plataformas de busca, acessa redes sociais, sites, editoriais e blogs especializados.

Segundo Motta e Batista (2013), o prosumidor normalmente se manifesta quando está satisfeito com o consumo e/ou para alertar sobre possíveis falhas, defeitos e qualquer outro problema que possa ter vivenciado no processo do consumo. Com isso, este autor observa certas mudanças na prática do marketing de produtos. O marketing tradicional, em seus moldes consagrados, já não se demonstra como um "caminho seguro", como postula esses autores. Os consumidores estão munidos de uma rede de informações com o advento da internet, portanto, anunciar que a empresa X é a mais barata já não é o suficiente para que as pessoas acreditem. 
DITO EFEITO - ISSN 1984-2376 -v. 6, n. 9, jul./dez. 2015-UTFPR CURITIBA -

http://periodicos.utfpr.edu.br/de

variáveis ao quão denegridos se sintam os clientes. (MOTTA; BATISTA, 2013, p. 41).

Além dos sites de compras, existem redes especializadas em coletar as informações dos consumidores, como o caso do Reclame Aqui, entre tantos outros, que possibilita que qualquer pessoa possua, através da rede, dados estatísticos de reclamações feitas por quem já consumiu o produto/serviço e, como corolário, acompanhe a resolução desses casos.

\section{Entre deboche, jornalismo e encenação: a marca Ades na tela virtual}

Para aprofundarmos esta investigação, procedemos a um estudo de cunho empírico, centrado na análise dos conteúdos dos vídeos postados na plataforma Youtube cuja temática centra-se no caso da adulteração do conteúdo líquido do suco Ades de sabor "maça", incidente ocorrido em 2013. A delimitação pelo estudo do material disponível no YouTube, plataforma fundada em fevereiro de 2005 com a principal função de armazenar e possibilitar o compartilhamento social de vídeos, funda-se no fato de que esse aparato tecnológico permite que pessoas e organizações possuam canais que possibilitam o envio e avaliações de produtos audiovisuais, comentários em fóruns e a interação a partir das inscrições em outros canais, práticas que podem representar distintas formas de mobilização e ativismo, individual e coletivamente.

A pesquisa valeu-se, primeiramente, de uma busca, neste canal, do termo "Ades de maçã", que gerou 691 resultados, no mês de janeiro de 2014. Desses resultados, analisamos os primeiros sessenta vídeos, que correspondem às três primeiras páginas da busca, pois são as constatações mais relevantes e com menor dispersão temática. De acordo com o conteúdo dos vídeos identificados, procedemos às categorizações temáticas, que são as seguintes:

Relatos pessoais: são os vídeos em que os próprios consumidores relatam o caso e fazem demonstração de como encontraram o suco.

Encenação: vídeos nos quais os consumidores montam um enredo e uma estrutura cênica, assumindo serem personagens na expressão de sua indignação.

Montagens com recursos midiáticos: montagens em que os consumidores utilizam-se de imagens já veiculadas por diferentes mídias, sobretudo a televisiva, com cenas e personagens que obtiveram considerável audiência.

Montagens específicas: montagens com a embalagem do suco em outras versões, envolvendo a criação de personagens próprios.

Vídeos jornalísticos: matérias que foram ao ar em canais do YouTube, para tratar da crise da marca. 
DITO EFEITO - ISSN 1984-2376 -v. 6, n. 9, jul./dez. 2015-UTFPR CURITIBA -

http://periodicos.utfpr.edu.br/de

Vídeos institucionais: vídeos institucionais ou promocionais da própria marca Ades.

Sem vínculo: quando os possuidores de canais no YouTube utilizaram o termo "ades de maçã" como descrição de um vídeo, no entanto, sem possuir qualquer vínculo com o caso tratado nesta investigação.

Em linhas gerais, podemos concluir que o caso de adulteração do conteúdo líquido do suco Ades de maçã obteve alta visibilidade nas mídias, o que pode ter sido a motivação para as manifestações dos prosumidores ativistas da marca, na plataforma virtual. Especificamente na mídia Youtube, os vídeos postados demonstram não apenas a diversidade de formas para se manifestar contrariamente à marca e ao caso específico, mas a dedicação e seriedade com que essa iniciativa ganha concretude. Por exemplo, alguns vídeos categorizados como "encenação", que somam nove materiais, apresentam produções bastante elaboradas, quiçá desenvolvidas por companhias de teatro. Só o fato de um grupo se mobilizar, reorganizar seu cotidiano para pensar e gravar uma cena na qual questiona o caso que aqui tratamos já aponta para a importância de que se reveste essa prática ativista.

Somando doze vídeos nos que foram classificados como "relatos pessoais", percebe-se que o consumidor sente a carência de um canal eficaz de comunicação com a marca, pois, ao que nos parece, utiliza a ferramenta com a esperança de obter uma resposta, já que, em seus discursos, são apresentados questionamentos sobre os custos, os prejuízos causados pela ingestão da bebida e sobre o receio, por parte dos pais, de o suco ter sido ingerido por crianças.

Juntos, os vídeos com "montagens de recursos midiáticos" e "montagens específicas" somam sete resultados. Nesses casos, os prosumidores utilizaram muita criatividade para, por exemplo, vincular a marca Ades à ideia de maçã venenosa da história ficcional da Branca de Neve e até mesmo inventar alienígenas falantes dentro das embalagens. O resgate mnemônico de enredos e personagens da infância intercruzam-se, de forma eloquente, a um fato real e problemático que acaba por ganhar ares de brincadeira e comicidade.

O YouTube também é muito utilizado por canais jornalísticos para a reprodução do conteúdo que foi ao ar na televisão. Dezoito vídeos se tratavam de "notícias jornalísticas" sobre o caso Ades de maçã, que legitimaram a relevância do ocorrido e contribuíram para que ele fosse ainda mais conhecido. O que se percebe, em particular, é a entrada, na internet, das mídias atualmente consideradas "tradicionais" ou, em outra percepção, a inexistência de disjunção entre os conteúdos veiculados nas mídias eletrônicas que têm amplo interesse público e os conteúdos que circulam no ciberespaço. Afinal, como já alertara Lévy (1999), o real o virtual não são instâncias cujas demarcações são circunscritas e socialmente respeitadas; ao contrário, 
DITO EFEITO - ISSN 1984-2376 -v. 6, n. 9, jul./dez. 2015-UTFPR CURITIBA -

http://periodicos.utfpr.edu.br/de

o sujeito contemporâneo vive no real virtualizado, assim como as mídias se intercruzam e se complementam, em múltiplas plataformas.

O canal "adesbrasil" possui atuação relativamente baixa. Dos sessenta vídeos que apareceram com a busca "ades de maçã", somente seis são "institucionais" da marca, sendo por vezes compartilhados por pessoas físicas. Por fim, é preciso mencionar que, ao cadastrar um vídeo, é necessário incluir palavras-chave sobre o assunto tratado para que ele seja, o mais diretamente possível, encontrado em buscas futuras.

$\mathrm{Na}$ presente pesquisa, verificamos que oito vídeos não tinham vínculo nenhum com o caso Ades de maçã, mas utilizaram o termo como palavra-chave. Entendemos que este fenômeno se trata de oportunismo para conseguir mais visualizações. Entre esses vídeos, havia o de uma consumidora que compartilhou a imagem de sua filha tomando o suco Ades de maçã, antes da adulteração do conteúdo acontecer.

\section{Conclusão}

O ciberespaço é um fenômeno que vem, nas últimas décadas, fazendo parte da vida de todos nós e influenciando em nossos costumes, crenças, hábitos e em nossas ações individuais e coletivas. Exemplo disso é o próprio prosumidor ativista, que atua virtualmente na legitimação ou descrédito da imagem de organizações e de suas marcas e participa, indiretamente, na tomada de decisão de inúmeros consumidores, podendo transformar os seus hábitos de consumo.

Esta pesquisa demonstra que existem diferentes formas de se manifestar na internet, e o YouTube é uma plataforma que oferece muitos recursos para as mobilizações de ativistas, já que os atores "comuns" da sociedade podem criar seus próprios canais e tornar públicos os seus conteúdos audiovisuais que criticam e questionam certa ordem ou paradigma vigente.

As manifestações do caso Ades de maçã mostram a diversidade que o ciberespaço oferece para os ativistas e para os prosumidores, que divulgam suas opiniões, livremente, sobre os produtos que consomem. Encontramos as mais variadas formas de vídeos, conforme classificamos, materiais, inclusive, tecnicamente muito bem produzidos, por canais que aparentam ser de companhias de teatro e de pessoas com capacidades técnicas elevadas, como produtores e cinegrafistas, ou que exigiram tempo e muita dedicação para a sua elaboração, revelando a seriedade embutida nas propostas. Nesse sentido, acreditamos que estudar os canais e os comentários no YouTube também pode nos oferecer resultados sobre a ação dos ativistas e 
DITO EFEITO - ISSN 1984-2376 -v. 6, n. 9, jul./dez. 2015-UTFPR CURITIBA -

http://periodicos.utfpr.edu.br/de

entender o que gera motivação para a produção dos vídeos, além dos motivos considerados "tradicionais".

Um ponto a considerar é que esses atos ativistas podem, ainda, gerar pressão nas organizações para que solucionem as falhas e problemas e, mais que isso, para que mantenham uma conduta responsável e ética. A imagem e a reputação institucional, afinal, colocam-se em xeque. Para se ter uma ideia, no final do mês de julho de 2014, o portal Terra publicou um texto com o seguinte título: "Brasil é $2^{\circ}$ mercado que mais consome vídeos no YouTube", o que nos faz pensar na importância dos conteúdos veiculados nesta plataforma.

E, ainda mais, no caso de gerenciamento de crises, como aconteceu com a marca Ades, o posicionamento e presença nas mídias digitais devem ser muito bem estabelecidos, e as organizações devem se lembrar de que essa e outras plataformas servem como importante canal de comunicação com seus públicos, que buscam rápidas respostas quando lançam mão dessas ferramentas. Sendo assim, reforçamos a atuação questionável da Ades Brasil frente a essa problemática, pois muitos consumidores, conforme verificado nos registros dos comentários no Youtube, ficaram sem receber qualquer contato a respeito, o que prejudica o relacionamento da marca com seus públicos.

\section{Referências}

CASTELLS, Manuel. A sociedade em rede. São Paulo: Paz e Terra, 1999. v. 1.

DOMINGUES, Izabela. Terrorismo de marca: publicidade, discurso e consumerismo político na rede. Pernambuco: Confraria do Vento, 2013.

FARIAS, Luís A. de (org.). Relações Públicas estratégicas: técnicas, conceitos e instrumentos. São Paulo: Summus, 2011.

FERRARI, Maria Aparecida. Cenário Latino-Americano da Comunicação e Relações Públicas. In: GRUNIG, James; FERRARI, Maria A.; FRANÇA, Fábio. Relações Públicas: teoria, contexto e relacionamento. São Caetano do Sul: Difusão Editora, 2011.

FORTES, Waldyr G. Relações Públicas: processo, funções, tecnologia e estratégias. São Paulo: Summus, 2003.

FRANÇA, Fábio. Públicos em Relações Públicas. In: GRUNIG, James; FERRARI, Maria A.; FRANÇA, Fábio. Relações Públicas: teoria, contexto e relacionamento. São Caetano do Sul: Difusão Editora, 2011.

GOHN, Maria da Glória. Teorias dos movimentos sociais. Paradigmas clássicos e contemporâneos. 9. ed. São Paulo: Loyola, 2011.

GRUNIG, James E. A função das relações públicas na administração e sua contribuição para a efetividade organizacional e societal. Trad. de John Franklin Arce. Comunicação \& Sociedade, São Bernardo do Campo: Póscom-Umesp, a. 24, 2003, n. 39, p. 67-92. 
. Uma teoria geral das relações públicas. In: GRUNIG, James: FERRARI, Maria A.; FRANÇA, Fábio. Relações Públicas: teoria, contexto e relacionamento. $2^{\mathrm{a}}$. ed. São Caetano do Sul: Difusão Editora, 2011.

HENRIQUES, Márcio Simeone. Ativismo, movimentos sociais e relações públicas. In:

KUNSCH, Margarida Maria Krohling; KUNSCH, Waldemar Luiz. Relações públicas comunitárias: a comunicação em uma perspectiva dialógica e transformadora. São Paulo: Summus, 2007.

JENKINS, Henry. Cultura da convergência. São Paulo; Aleph, 2008.

KAUFMAN, Dora. ROZA, Erick. Empresas e consumidores em rede: um estudo das práticas colaborativas no Brasil. São Paulo: Annablume, 2013.

LÉVY, Pierre. Cibercultura. São Paulo: Editora 34, 1999.

Pela ciberdemocracia. In: MORAES, Dênis de (org.). Por uma outra comunicação: mídia, mundialização cultural e poder. Rio de Janeiro: Editora Record, 2012.

MACHADO, Jorge Alberto S. Ativismo em rede e conexões identitárias: novas perspectivas para os movimentos sociais. Sociologias, Porto Alegre, ano 9, nº 18, 2007.

MAZETTI, Henrique Moreira. O expressivismo como contestação midiática. Disponível em: http://seer.utp.br/index.php/vol11/article/view/104/92. Acesso em: 10 jun. 2013.

MORAES, Dênis de. Comunicação alternativa, redes virtuais e ativismo: avanços e dilemas.

Revista de Economía Política de las Tecnologías de la Información y Comunicación, vol. IX, n. 2, mayo - ago. / 2007. Disponível em:

http://www.observatoriodaimprensa.com.br/download/Comunicacao_alternativa.pdf. Acesso em: 07 de jun. 2013.

MOTTA, Bruna; BATISTA, Leandro L. A crença no desconhecido: como a prossumerização está mudando os hábitos de consumo. Cadernos de comunicação, v.17, n.18, jan-jun. 2013.

PERUZZO, Cicília. Comunicação nos movimentos populares: a participação na construção da cidadania. $3^{\text {a }}$.ed. Petrópolis: Vozes, 2004. 